
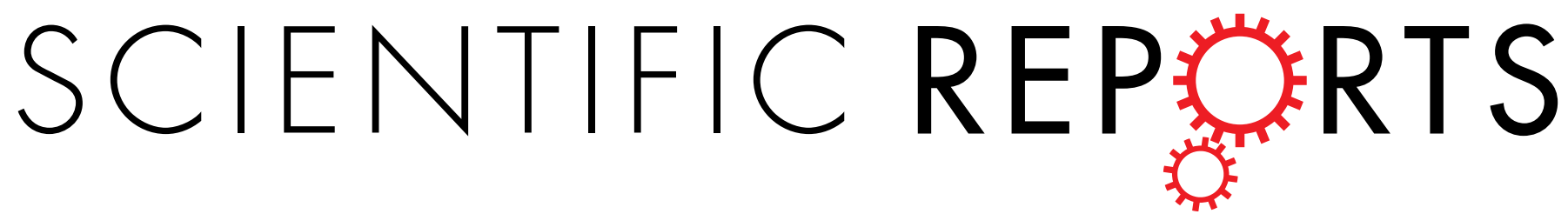

\title{
OPEN Refractive Errors and Concomitant Strabismus: A Systematic Review and Meta-analysis
}

Received: 02 June 2016

Accepted: 26 September 2016

Published: 12 October 2016
Shu Min Tang ${ }^{1, *}$, RachelY. T. Chan ${ }^{1, *}$, Shi Bin Lin ${ }^{2, *}$, Shi Song Rong ${ }^{1,{ }^{\dagger}}$, Henry H. W. Lau ${ }^{1}$, Winnie W. Y. Lau ${ }^{1}$, Wilson W. K. Yip ${ }^{1}$, Li Jia Chen ${ }^{1,2}$, Simon T. C. Ko ${ }^{3}$ \& Jason C. S. Yam ${ }^{1,2}$

This systematic review and meta-analysis is to evaluate the risk of development of concomitant strabismus due to refractive errors. Eligible studies published from 1946 to April 1, 2016 were identified from MEDLINE and EMBASE that evaluated any kinds of refractive errors (myopia, hyperopia, astigmatism and anisometropia) as an independent factor for concomitant exotropia and concomitant esotropia. Totally 5065 published records were retrieved for screening, 157 of them eligible for detailed evaluation. Finally 7 population-based studies involving 23,541 study subjects met our criteria for metaanalysis. The combined OR showed that myopia was a risk factor for exotropia (OR: 5.23, $\mathrm{P}=0.0001$ ). We found hyperopia had a dose-related effect for esotropia (OR for a spherical equivalent [SE] of 2-3 diopters [D]: 10.16, P = 0.01; OR for an SE of 3-4D: 17.83, P < 0.0001; OR for an SE of 4-5D: 41.01, $P<0.0001$; OR for an SE of $\geq 5 \mathrm{D}: 162.68, \mathrm{P}<0.0001$ ). Sensitivity analysis indicated our results were robust. Results of this study confirmed myopia as a risk for concomitant exotropia and identified a doserelated effect for hyperopia as a risk of concomitant esotropia.

Strabismus, a misalignment of both eyes, is a common ocular disorder in childhood populations. The prevalence estimates for concomitant strabismus ranged from $2.3 \%$ to $6.0 \%$ in children ${ }^{1,2}$. The consequences of strabismus can be devastating. First, it would lead to loss of binocularity and depth perception. It is also the most common cause of amblyopia, and as such contributes importantly to childhood visual impairment ${ }^{3,4}$. In particular, the long-term surgical successes for strabismus (such as intermittent exotropia) are not satisfactory, with only around $50 \%$ success 3 -year after the operation ${ }^{5,6}$. In additional to these functional effects, it also has significant psychosocial consequences in terms of self-image ${ }^{4,7}$, negative social prejudice ${ }^{8,9}$ and even lower chance to get employed ${ }^{10}$.

The pathogenesis of different types of concomitant strabismus has not been well established. Many researchers have studied the association between accommodative esotropia and hyperopia ${ }^{11,12}$. However, the degree of increased risk of accommodative esotropia in relation to the severity of hyperopia is not well documented. On the other hand, the observed higher prevalence of concomitant exotropia in Asian ${ }^{11,13}$ than Caucasians has been postulated to be related to the high prevalence of myopia $^{14,15}$, but this relationship has not been well substantiated. Furthermore, the association between other types of refractive errors (such as astigmatism and anisometropia) and different types of concomitant strabismus is not clear. Indeed, confirming these relationships is important, because it can provide insights into the pathophysiology of concomitant strabismus; as well as providing guideline on the managements of refractive error in the aspect of preventing strabismus development ${ }^{14}$. In this systematic review and meta-analysis, we aimed to evaluate the risks of development of different types of concomitant strabismus in relation to all types of refractive errors.

\section{Method}

Search Strategies. Literature search was performed via the Ovid platform in MEDLINE (available in the public domain at http://www.nlm.nih.gov/bsd/licensee/medpmmenu.html) and EMBASE (available in the public domain at http:www.embase.com/info/helpfiles/) database from their starting date to April 1, 2016. The Boolean logic was adopted in the search strategy. The following keywords were used as free words and also as MeSH terms:

${ }^{1}$ Department of Ophthalmology and Visual Sciences, The Chinese University of Hong Kong, Hong Kong. ${ }^{2}$ Joint Shantou International Eye Center, Shantou University and The Chinese University of Hong Kong, Shantou, China. ${ }^{3}$ Department of Ophthalmology, Tung Wah Eastern Hospital, Hong Kong. ${ }^{\dagger}$ Present address: Massachusetts Eye and Ear Infirmary, Boston, MA, USA *These authors contributed equally to this work. Correspondence and requests for materials should be addressed to J.C.S.Y. (email: yamcheuksing@cuhk.edu.hk) 


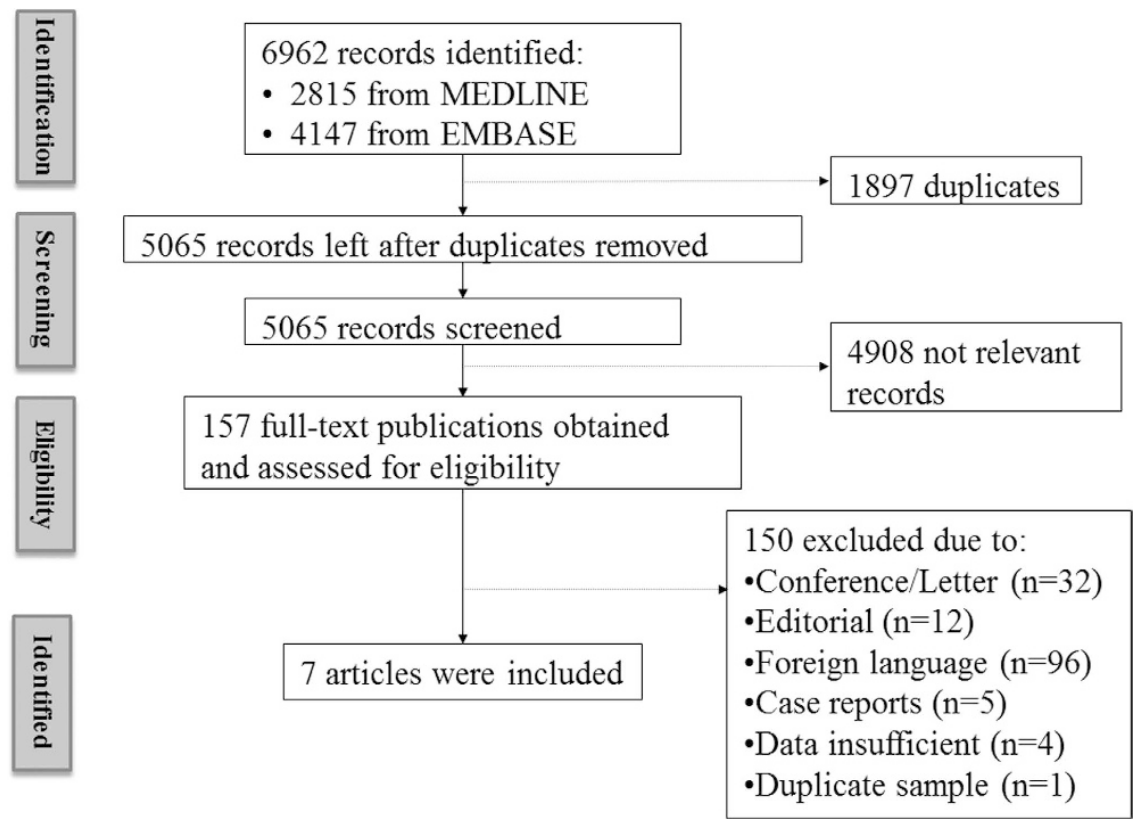

Figure 1. Flowchart of study inclusion.

"strabismus", “esotropia”, “exotropia”, "refractive errors”, “myopia”, "hyperopia” and "anisometropia”. Detailed search strategies were given in Supplementary Table 1. Reference lists of the eligible articles and reviews were manually screened for additional articles, if any, that had not been captured by the electronic search.

Eligibility Criteria. The inclusion criteria for eligible studies were as follows: (1) population-based cross-sectional study; (2) the status of strabismus (heterotropia) was diagnosed by cover and uncover test; (3) refractive error of both eyes was documented; (4) the numbers or frequencies of strabismus and non-strabismus in each type of refractive error were reported, or odds ratio (OR) and 95\% confidence interval (95\% CI) of different refractive errors for strabismus were estimated. We excluded animal studies, case reports, reviews, abstracts, conference proceedings, editorials, non-English articles and reports with incomplete data.

Data Extraction. All retrieved records were screened and reviewed by two independent reviewers (SMT and RYTC). Uncertainties were resolved by consensus with a third reviewer (JCSY). Data collected from each study included (1) study information including year of publication, country of study, age range of participants, definition of different refractive errors (including myopia, hyperopia, astigmatism and anisometropia), sample sizes; (2) numbers of strabismus in subjects with and without refractive errors, reported unadjusted and adjusted ORs and 95\% CIs (or standard errors), and adjusted co-variables; and (3) numbers of esotropia and exotropia in subjects with and without refractive errors, if provided.

Risk of Bias Assessment. All included studies were population-based cross-sectional studies. Therefore, the quality of studies was assessed via the modified Estabrooks' Quality Assessment and Validity Tool ${ }^{16}$ by two reviewers (SMT and RYTC) independently, and disagreements were resolved through discussion with a third reviewer (JCSY). The modified Estabrooks' tool contains 14 items, which were divided into two groups. Group I included probabilistic sample used, sample size appropriate for power, response rate exceeding 50\%, validity, appropriate tests used, and CI reported. Group II included representative sample, sample drawn from multiple sites, cluster/stratified design, multiple adjusted, detective variable [primary outcome] directly measured/administrative, reliability, $\mathrm{P}$ values reported, and missing data managed appropriately. Study was considered to be of high risk when one item in Group I was marked as "No" or two items marked as "N/A", or any two items from Group II marked as "No" or three items marked as "N/A"16.

Data Analysis. We evaluated the association between concomitant strabismus and refractive errors by synthesizing the outcomes using meta-analysis. Among the eligible studies, four studies have classified concomitant strabismus into esotropia and exotropia ${ }^{11,12,17,18}$. We assessed the association of exotropia and esotropia with different kinds of refractive errors, i.e., myopia, hyperopia, astigmatism and anisometropia. The combined odds ratios (ORs) with 95\% confidence intervals (CIs) of refractive errors as associated factors for exotropia and esotropia were analyzed. The Cochran Q statistic testing for heterogeneity across studies and the $\mathrm{I}^{2}$ statistic quantifying the proportion of total variation attributable to between-study heterogeneity were calculated ${ }^{19}$. The $\mathrm{P}$ value of $\mathrm{Q}$ statistics lower than 0.1 and $\mathrm{I}^{2}$ above $50 \%$ indicated high heterogeneity. If significant heterogeneity was detected, result from the random-effect model was adopted ${ }^{20}$, otherwise, the fixed-effect model was used ${ }^{21}$. Two articles have stratified hyperopia into different severities (SE of 2-3D, SE of 3-4D, SE of 4-5D and SE of $>5 D$ ), therefore ORs and $95 \%$ CIs of were combined to compare the risk of esotropia. Sensitivity analysis was performed to confirm the association by removing studies of higher risk of introducing bias. We also assessed the contribution 


\begin{tabular}{|c|c|c|c|c|c|c|c|c|c|c|c|c|}
\hline \multirow[b]{2}{*}{$\begin{array}{l}\text { First } \\
\text { Author }\end{array}$} & \multirow[b]{2}{*}{ Study-design } & \multirow[b]{2}{*}{$\begin{array}{l}\text { Location } \\
\text { of Study }\end{array}$} & \multirow[b]{2}{*}{$\begin{array}{c}\text { Sample } \\
\text { size }\end{array}$} & \multirow[b]{2}{*}{ Age } & \multirow[b]{2}{*}{ Strabismus } & \multicolumn{5}{|c|}{ Definition } & \multirow[b]{2}{*}{$\begin{array}{c}\text { Adjusted factors } \\
\text { for multivariate } \\
\text { analysis }\end{array}$} & \multirow[b]{2}{*}{ References } \\
\hline & & & & & & Myopia & Hyperopia & Astigmatism & Anisometropia & $\begin{array}{c}\text { Absent of } \\
\text { significant } \\
\text { ametropia }\end{array}$ & & \\
\hline $\begin{array}{l}\text { Robaei D } \\
2006\end{array}$ & $\begin{array}{l}\text { population- } \\
\text { based cross- } \\
\text { sectional }\end{array}$ & $\begin{array}{l}\text { Sydney, } \\
\text { AU }\end{array}$ & 2352 & $12 \mathrm{y}$ & $\begin{array}{l}\text { Any heterotropia } \\
\text { at near or distance } \\
\text { fixation, or both. }\end{array}$ & $\mathrm{SE} \leq-0.50 \mathrm{D}$ & $\begin{array}{l}\mathrm{SE} \geq+ \\
2.00 \mathrm{D}\end{array}$ & $\begin{array}{c}\text { cylinder } \\
\mathrm{D}\end{array}$ & $\begin{array}{c}\mathrm{SE} \\
\text { difference } \geq 1.00 \mathrm{D}\end{array}$ & $\left|\begin{array}{c}-0.50 \mathrm{D}<\mathrm{SE} \\
<+2.00 \mathrm{D}\end{array}\right|$ & N.A. & 11 \\
\hline $\begin{array}{l}\text { Robaei D } \\
2006\end{array}$ & $\begin{array}{l}\text { population- } \\
\text { based cross- } \\
\text { sectional }\end{array}$ & $\begin{array}{l}\text { Sydney, } \\
\text { AU }\end{array}$ & 1740 & $6 y$ & \begin{tabular}{|c|} 
Any heterotropia \\
at near $(30 \mathrm{~cm})$ \\
or distance $(6 \mathrm{~m})$ \\
fixation, or both.
\end{tabular} & $\mathrm{SE} \leq-0.50 \mathrm{D}$ & $\begin{array}{l}\mathrm{SE} \geq+ \\
2.00 \mathrm{D}\end{array}$ & $\begin{array}{c}\text { cylinder } \\
\mathrm{D}\end{array}$ & $\begin{array}{c}\mathrm{SE} \\
\text { difference } \geq 1.00 \mathrm{D}\end{array}$ & $\begin{array}{c}-0.50 \mathrm{D}<\mathrm{SE} \\
<+2.00 \mathrm{D}\end{array} \mid$ & $\begin{array}{c}\text { clustering within } \\
\text { school }\end{array}$ & 23 \\
\hline $\begin{array}{l}\text { Huynh SC } \\
2006\end{array}$ & $\begin{array}{l}\text { population- } \\
\text { based cross- } \\
\text { sectional }\end{array}$ & $\begin{array}{l}\text { Sydney, } \\
\text { AU }\end{array}$ & 1765 & $6 y$ & $\begin{array}{l}\text { Any heterotropia } \\
\text { at near }(30 \mathrm{~cm}) \\
\text { or distance }(6 \mathrm{~m}) \\
\text { fixation, or both. }\end{array}$ & N.A. & N.A. & N.A. & $\begin{array}{c}\mathrm{SE} \\
\text { difference } \geq 1.00 \mathrm{D}\end{array}$ & $\mid \begin{array}{c}-0.50 \mathrm{D}<\mathrm{SE} \\
<+2.00 \mathrm{D}\end{array}$ & $\begin{array}{l}\text { Refraction, } \\
\text { multiple birth } \\
\text { and amblyopia }\end{array}$ & 17 \\
\hline $\begin{array}{l}\text { Cotter SA } \\
2011\end{array}$ & $\begin{array}{l}\text { population- } \\
\text { based cross- } \\
\text { sectional }\end{array}$ & $\begin{array}{c}\text { California } \\
\text { and } \\
\text { Maryland, } \\
\text { USA }\end{array}$ & 8491 & $6-72 \mathrm{~m}$ & \begin{tabular}{|c|} 
Constant or \\
intermittent \\
heterotropia of \\
any magnitude at \\
distance or near \\
fixation, or both.
\end{tabular} & $\mathrm{SE} \leq-1.00 \mathrm{D}$ & $\begin{array}{l}\mathrm{SE} \geq+ \\
2.00 \mathrm{D}\end{array}$ & $\begin{array}{c}\text { cylinder } \\
\mathrm{D}\end{array}$ & $\begin{array}{c}\mathrm{SE} \\
\text { difference } \geq 1.00 \mathrm{D}\end{array}$ & $\mid \begin{array}{c}-1.00 \mathrm{D}<\mathrm{SE} \\
<+2.00 \mathrm{D}\end{array}$ & \begin{tabular}{|c|} 
gender, \\
gestational age, \\
age, maternal \\
smoking during \\
pregancy
\end{tabular} & 12 \\
\hline $\begin{array}{l}\text { Chia A } \\
2013\end{array}$ & $\begin{array}{l}\text { population- } \\
\text { based cross- } \\
\text { sectional }\end{array}$ & Singapore & 2992 & 6-72m & $\begin{array}{l}\text { Any manifest } \\
\text { tropia identified } \\
\text { on cover test. }\end{array}$ & $\mathrm{SE} \leq-0.50 \mathrm{D}$ & $\begin{array}{l}\mathrm{SE} \geq+ \\
0.50 \mathrm{D}\end{array}$ & $\begin{array}{c}\text { cylinder } \\
\mathrm{D}\end{array}$ & $\begin{array}{c}\mathrm{SE} \\
\text { difference } \geq 1.00 \mathrm{D}\end{array}$ & $\mid \begin{array}{c}-0.50 \mathrm{D}<\mathrm{SE} \\
<+0.50 \mathrm{D}\end{array}$ & $\begin{array}{l}\text { age, gender, } \\
\text { gestational age, } \\
\text { admission to } \\
\text { NICU, father's } \\
\text { education, } \\
\text { sibling with } \\
\text { strabismus, } \\
\text { concurrent } \\
\text { amblyopia }\end{array}$ & 24 \\
\hline Fu J 2014 & $\begin{array}{l}\text { population- } \\
\text { based cross- } \\
\text { sectional }\end{array}$ & $\begin{array}{l}\text { AnYang, } \\
\text { China }\end{array}$ & 2151 & $10-16 y$ & $\begin{array}{c}\text { A heterotropia } \\
\text { at near and/or } \\
\text { distance fixation. }\end{array}$ & $\mathrm{SE} \leq-0.50 \mathrm{D}$ & $\begin{array}{l}\mathrm{SE} \geq+ \\
0.50 \mathrm{D}\end{array}$ & $\begin{array}{c}\text { cylinder } \geq \\
\mathrm{D}\end{array}$ & $\begin{array}{c}\mathrm{SE} \\
\text { difference } \geq 1.00 \mathrm{D}\end{array}$ & $\begin{array}{c}-0.50 \mathrm{D}<\mathrm{SE} \\
<+0.50 \mathrm{D}\end{array}$ & N.A. & 1 \\
\hline $\begin{array}{l}\text { Zhu H } \\
2015\end{array}$ & $\begin{array}{l}\text { population- } \\
\text { based cross- } \\
\text { sectional }\end{array}$ & $\begin{array}{l}\text { Nanjing, } \\
\text { China }\end{array}$ & 5831 & $3-6 y$ & $\begin{array}{c}\text { Any tropia at } \\
\text { distance or near, } \\
\text { with or without } \\
\text { spectacles }\end{array}$ & $\mathrm{SE} \leq-1.00 \mathrm{D}$ & $\begin{array}{l}\mathrm{SE} \geq+ \\
2.00 \mathrm{D}\end{array}$ & $\begin{array}{c}\text { cylinder } \geq 1.00 \\
\mathrm{D}\end{array}$ & $\begin{array}{c}\mathrm{SE} \\
\text { difference } \geq 1.00 \mathrm{D}\end{array}$ & $\begin{array}{c}-1.00 \mathrm{D}<\mathrm{SE} \\
<+2.00 \mathrm{D}\end{array}$ & age and gender & 18 \\
\hline
\end{tabular}

Table 1. Summary of Included Studies.

of each study to the heterogeneity by sequentially omitting each study and recalculating the combined ORs. The Modified Egger's regression test was used to assess the potential publication bias, where a P value less than 0.05 was considered statistically significant ${ }^{22}$. The Review Manager software (RevMan, version 5.2; the Nordic Cochrane Centre, The Cochrane Collaboration, Copenhagen; 2012) was used for data analysis. The Stata software (version 12; StataCorp LP, College Station, TX) was used to validate the results and perform the Egger's test. $P$ values less than 0.05 were considered statistical significant.

\section{Results}

From 1946 to April 1 of 2016, a total of 6962 publications were identified from the EMBASE and MEDLINE databases. After detailed screening and evaluation, 157 reports were eligible for detailed evaluation. Among them, we found 7 articles ${ }^{1,11,12,17,18,23,24}$ meeting our criteria for meta-analysis (Fig. 1). All these articles were population-based cross-sectional studies with the strabismus status and refractive error status of all included cases clearly documented. The studies spread across different ethnic groups, including Caucasian ${ }^{11,12,17,23}$ and East Asian ${ }^{1,18,24}$. Strabismus of all studies was evaluated using the cover-uncover test to define as any heterotropia at distant or near distance with or without spectacles. Cases of heterophoria were not eligible for the meta-analysis, and were excluded. Refractive errors, including myopia, hyperopia, astigmatism and anisometropia, were measured under cycloplegic condition in all included studies (Table 1). Overall, 23,541 subjects with age ranging from 6 months to 12 years were recruited for the meta-analysis in these 7 studies. Four articles ${ }^{11,12,17,18}$ have studied the association between refractive errors and different types of strabismus (including exotropia and esotropia). Three articles ${ }^{12,17,18}$ reported adjusted ORs and 95\% CI for esotropia and exotropia, respectively. Factors that were usually adjusted included age, gender and refraction ${ }^{12,17,18}$ (Table 1).

Association between myopia and concomitant strabismus. Six out of seven studies ${ }^{1,11,12,18,23,24}$ have evaluated association between myopia and concomitant strabismus. Subjects with myopia had increased risk of developing concomitant strabismus (OR: 3.22, 95\% CI: 1.84-5.65, $\mathrm{I}^{2}=65 \%, \mathrm{P}<0.0001$; Table 2, Fig. 2A). In subgroup analysis by strabismus subtypes pooled up by three studies ${ }^{11,12,18}$ (for myopia and hyperopia separately), myopia was associated with exotropia (OR: 5.23, 95\% CI: 2.26-12.09, $\mathrm{I}^{2}=69 \%, \mathrm{P}=0.0001$; Table 3, Fig. 2B) but not associated with esotropia (OR: $2.07,95 \%$ CI: $0.87-4.93, \mathrm{I}^{2}=43 \%, \mathrm{P}=0.1$; Table 3 , Fig. $2 \mathrm{C}$ ). In the analysis using adjusted outcomes, myopia was associated with exotropia; but not associated with esotropia (OR: 2.63, $95 \%$ CI: $1.02-6.78, \mathrm{I}^{2}=0 \%, \mathrm{P}=0.05$ ) (Table 4 ). Only Zhu's paper ${ }^{18}$ has provided the adjusted OR for myopia and exotropia, which showed that myopia remained associated with exotropia after adjusting for age, gender and refraction. 


\begin{tabular}{|c|c|c|c|c|c|c|c|c|c|}
\hline \multirow[b]{2}{*}{ Type of exposure } & \multirow{2}{*}{$\begin{array}{c}\text { No of } \\
\text { Studies }\end{array}$} & \multirow{2}{*}{$\begin{array}{c}\text { Sample } \\
\text { size }\end{array}$} & \multicolumn{3}{|c|}{ Overall effect } & \multicolumn{2}{|c|}{ Heterogeneity } & \multirow[b]{2}{*}{ Egger's } & \multirow[b]{2}{*}{ Reference } \\
\hline & & & OR ( $95 \% \mathrm{CI})$ & z score & P Value & $I^{2}, \%$ & $\mathbf{Q}(\mathbf{P})$ & & \\
\hline Myopia & 6 & 19597 & $\begin{array}{c}3.22 \\
(1.84-5.65)\end{array}$ & 4.09 & $<0.0001$ & $65 \%$ & 0.01 & 0.813 & $1,11,12,18,23,24$ \\
\hline Hyperopia & 6 & 20818 & $\begin{array}{c}4.29 \\
(1.67-10.99)\end{array}$ & 3.03 & 0.002 & $95 \%$ & $<0.0001$ & 0.541 & $1,11,12,18,23,24$ \\
\hline Astigmatism & 6 & 23541 & $\begin{array}{c}3.27 \\
(2.08-5.15)\end{array}$ & 5.13 & $<0.0001$ & $76 \%$ & 0.001 & 0.349 & $1,11,12,18,23,24$ \\
\hline Anisometropia & 6 & 23541 & $\begin{array}{c}5.68 \\
(2.44-13.23)\end{array}$ & 4.03 & $<0.0001$ & $92 \%$ & $<0.0001$ & 0.505 & $1,11,12,18,23,24$ \\
\hline
\end{tabular}

Table 2. Meta-analysis of Association of Refractive Errors with Strabismus.

A

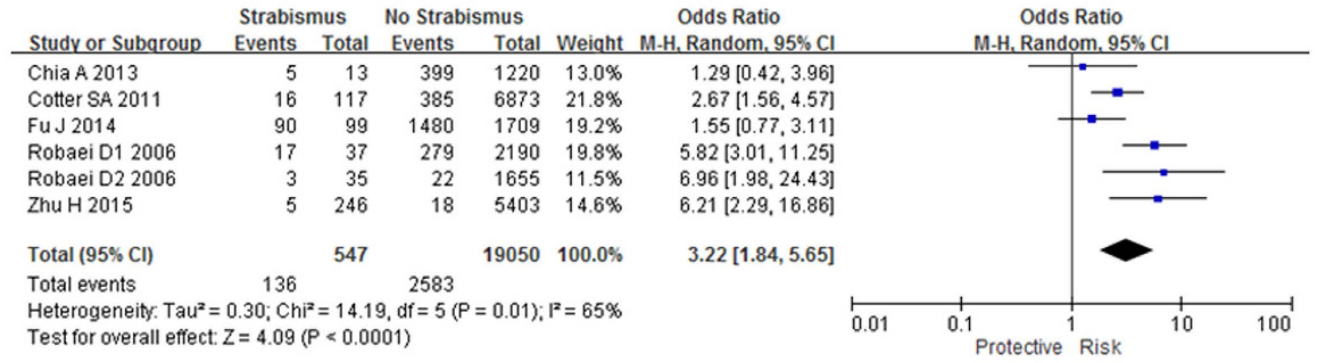

B

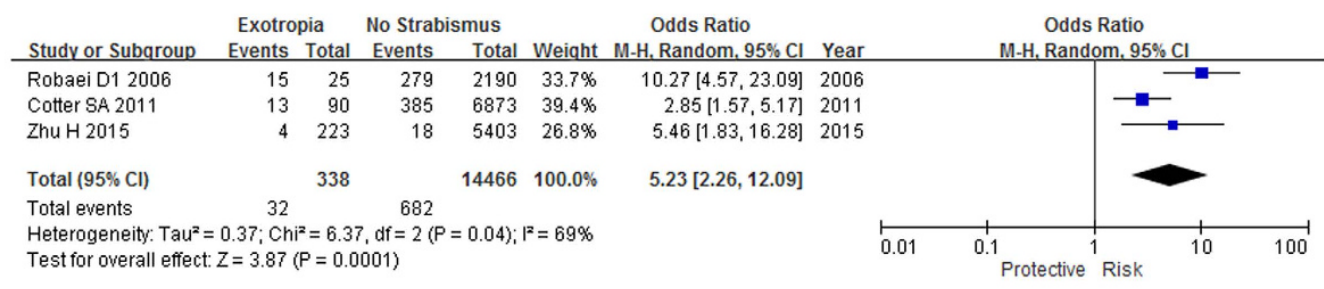

C

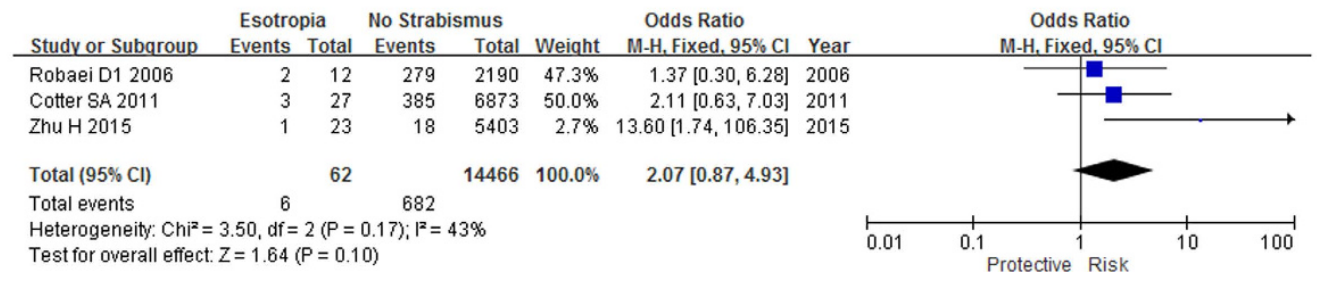

Figure 2. Meta-analysis of the association of myopia with different types of strabismus. The bars with squares in the middle represent $95 \%$ confidence intervals (95\% CIs) and odds ratios (ORs). The central vertical solid line indicates the ORs for the null hypothesis. Diamond indicates summary OR with its corresponding 95\% CI. (A) Association between myopia and strabismus. (B) Association between myopia and exotropia.

(C) Association between myopia and esotropia.

Association between hyperopia and concomitant strabismus. Six out of seven studies 1,11,12,18,23,24 have evaluated association between hyperopia and concomitant strabismus. Hyperopia was strongly associated with concomitant strabismus (OR: 4.29, 95\% CI: 1.67-10.99, $\mathrm{I}^{2}=95 \%, \mathrm{P}=0.002$; Table 2, Fig. 3A). Three studies $^{11,12,18}$ have evaluated association between hyperopia and esotropia; and exotropia separately. The subgroup analysis showed that hyperopia was a risk factor for esotropia (OR: $22.95,95 \%$ CI: 9.68-54.41, $\mathrm{I}^{2}=81 \%$, $\mathrm{P}<0.0001$; Table 3, Fig. 3C), but not for exotropia (OR: 3.05, 95\% CI: 0.34-27.22, $\mathrm{I}^{2}=97 \%, \mathrm{P}=0.32$; Table 3, Fig. 3B). Based on the severity of hyperopia, hyperopia was divided into 2-3D, 3-4D, 4-5D and higher than 5D. The risk of esotropia was increased with the severity of hyperopia (OR for a SE of 2-3D: 10.16; OR for a SE of 3-4D: 17.83; OR for a SE of 4-5D: 41.01; OR for a SE of $\geq 5 \mathrm{D}: 162.68$; Table 5). Of note, after adjusted for age and gender, the association was still remained. (OR of $\mathrm{SE}=2-3 \mathrm{D}: 7.26$, OR of $\mathrm{SE}=3-4 \mathrm{D}: 19.45$, OR of $\mathrm{SE}=4-5 \mathrm{D}$ : 44.86, OR of SE $\geq 5 \mathrm{D}$ : 134.19 ; Table 4).

Association between astigmatism and concomitant strabismus. Six out of seven studies ${ }^{1,11,12,18,23,24}$ have evaluated association between astigmatism and concomitant strabismus. Astigmatism was associated with concomitant strabismus (OR: 3.27, 95\% CI: 2.08-5.15, $\mathrm{I}^{2}=76 \%, \mathrm{P}<0.0001$; Table 2, Fig. 4A). Three studies $^{11,12,18}$ have evaluated association between astigmatism and exotropia; and esotropia separately. The subgroup 


\begin{tabular}{|c|c|c|c|c|c|c|c|c|c|}
\hline \multirow[b]{2}{*}{ Type of exposure } & \multirow{2}{*}{$\begin{array}{l}\text { No of } \\
\text { Studies }\end{array}$} & \multirow{2}{*}{$\begin{array}{l}\text { Sample } \\
\text { size }\end{array}$} & \multicolumn{3}{|c|}{ Overall effect } & \multicolumn{2}{|c|}{ Heterogeneity } & \multirow[b]{2}{*}{ Egger's } & \multirow[b]{2}{*}{ Reference } \\
\hline & & & OR $(95 \% \mathrm{CI})$ & z score & P Value & $I^{2, \%}$ & $\mathbf{Q}(\mathbf{P})$ & & \\
\hline \multicolumn{10}{|c|}{ Association with exotropia } \\
\hline Myopia & 3 & 14804 & $\begin{array}{c}5.23 \\
(2.26-12.09)\end{array}$ & 3.87 & 0.0001 & $69 \%$ & 0.04 & 0.571 & $11,12,18$ \\
\hline Hyperopia & 3 & 15776 & $\begin{array}{c}3.05 \\
(0.34-27.22) \\
\end{array}$ & 1 & 0.32 & $97 \%$ & $<0.0001$ & 0.682 & $11,12,18$ \\
\hline Astigmatism & 3 & 16490 & $\begin{array}{c}3.2 \\
(2.29-4.48)\end{array}$ & 6.79 & $<0.0001$ & $0 \%$ & 0.39 & 0.720 & $11,12,18$ \\
\hline Anisometropia & 4 & 18192 & $\begin{array}{c}6.56 \\
(3.19-13.49)\end{array}$ & 5.11 & $<0.0001$ & $72 \%$ & 0.01 & 0.951 & $11,12,17,18$ \\
\hline \multicolumn{10}{|c|}{ Association with esotropia } \\
\hline Myopia & 3 & 14528 & $\begin{array}{c}2.07 \\
(0.87-4.93)\end{array}$ & 1.64 & 0.1 & $43 \%$ & 0.17 & 0.454 & $11,12,18$ \\
\hline Hyperopia & 3 & 15571 & $\begin{array}{c}22.95 \\
(9.68-54.41)\end{array}$ & 7.11 & $<0.0001$ & $81 \%$ & 0.005 & 0.483 & $11,12,18$ \\
\hline Astigmatism & 3 & 16259 & $\begin{array}{c}2.95 \\
(2.03-4.29)\end{array}$ & 5.66 & $<0.0001$ & $3 \%$ & 0.36 & 0.344 & $11,12,18$ \\
\hline Anisometropia & 4 & 17961 & $\begin{array}{c}11.29 \\
(4.22-30.23)\end{array}$ & 4.82 & $<0.0001$ & $83 \%$ & 0.0006 & 0.585 & $11,12,17,18$ \\
\hline
\end{tabular}

Table 3. Meta-analysis of Association of Refractive Errors with Exotropia and Esotropia.

A

\begin{tabular}{|c|c|c|c|c|c|c|c|}
\hline \multirow[b]{2}{*}{ Study or Subqroup } & \multicolumn{2}{|c|}{ Strabismus } & \multicolumn{2}{|c|}{ No Strabismus } & \multicolumn{3}{|c|}{ Odds Ratio } \\
\hline & Events & Total & Events & Total & Weight & M.H. Random. $95 \% \mathrm{Cl}$ & Yea \\
\hline Robaei D1 2006 & 11 & 31 & 98 & 2009 & $16.4 \%$ & $10.72[5.00,23.01]$ & \\
\hline Robaei D2 2006 & 13 & 45 & 37 & 1670 & $16.5 \%$ & $17.93[8.71,36.92]$ & \\
\hline Cotter SA 2011 & 87 & 188 & 1414 & 7902 & $18.0 \%$ & $3.95[2.95,5.29]$ & \\
\hline Chia A 2013 & 11 & 19 & 1744 & 2565 & $15.6 \%$ & $0.65[0.26,1.62]$ & \\
\hline Fu J 2014 & 9 & 18 & 334 & 563 & $15.5 \%$ & $0.69[0.27,1.75]$ & \\
\hline Zhu H 2015 & 69 & 310 & 113 & 5498 & $17.9 \%$ & $13.64[9.85,18.90]$ & \\
\hline Total $(95 \% \mathrm{Cl})$ & & 611 & & 20207 & $100.0 \%$ & $4.29[1.67,10.99]$ & \\
\hline Total events & 200 & & 3740 & & & & \\
\hline
\end{tabular}

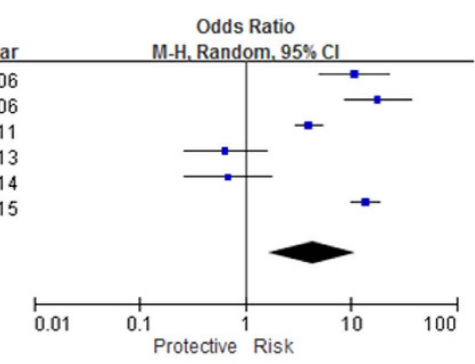

B

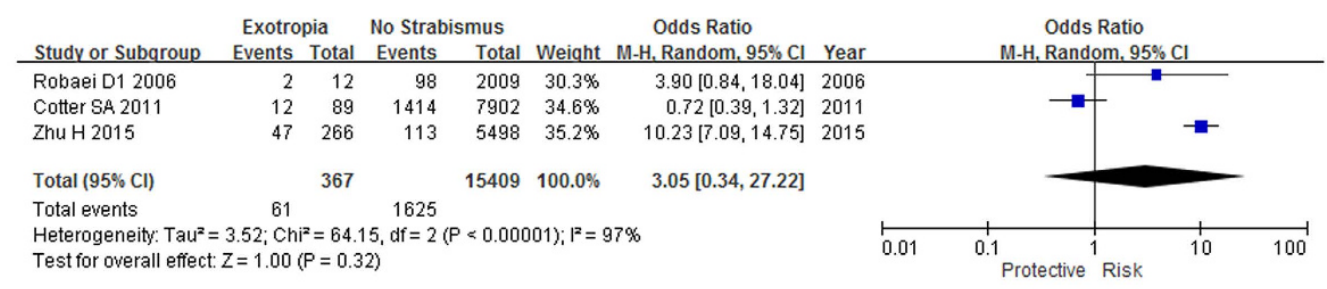

C

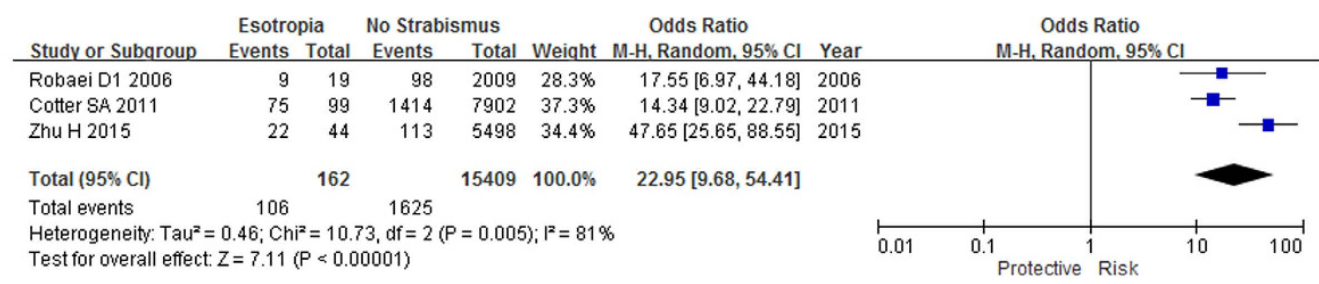

Figure 3. Meta-analysis of the association of hyperopia with different types of strabismus. The bars with squares in the middle represent $95 \%$ confidence intervals (95\% CIs) and odds ratios (ORs). The central vertical solid line indicates the ORs for the null hypothesis. Diamond indicates summary OR with its corresponding 95\% CI. (A) Association between hyperopia and strabismus. (B) Association between hyperopia and exotropia. (C) Association between hyperopia and esotropia.

analysis showed that astigmatism was associated with both the exotropia (OR: 3.20, 95\% CI: $2.29-4.48, \mathrm{I}^{2}=0 \%$, $\mathrm{P}<0.0001$; Table 3, Fig. 4B) and the esotropia (OR: 2.95, 95\% CI: 2.03-4.29, $\mathrm{I}^{2}=3 \%, \mathrm{P}<0.0001$; Table 3, Fig. 4C). However, the associations of astigmatism with exotropia and esotropia became insignificant when using the adjusted ORs $(\mathrm{P}=0.73$; Table 4$)$. Only Zhu's $\operatorname{paper}^{18}$ has provided the adjusted OR for astigmatism and exotropia (OR: $1.06,95 \% \mathrm{CI}: 0.34-3.28, \mathrm{P}=0.919$ ), in which the association could not withstand the adjustment. 


\begin{tabular}{|c|c|c|c|c|c|c|c|}
\hline \multirow[b]{2}{*}{ Type of exposure } & \multirow{2}{*}{$\begin{array}{l}\text { No of } \\
\text { Studies }\end{array}$} & \multicolumn{3}{|c|}{ Overall effect } & \multicolumn{2}{|c|}{ Heterogeneity } & \multirow[b]{2}{*}{ Reference } \\
\hline & & OR $(95 \% \mathrm{CI})$ & z score & P Value & $I^{2, \%}$ & $\mathbf{Q}(\mathbf{P})$ & \\
\hline myopia vs esotropia & 2 & $2.63(1.02-6.78)$ & 2 & 0.05 & $0 \%$ & 0.77 & 12,18 \\
\hline hyperopia (2-3D) vs esotropia & 2 & $7.26(3.46-15.22)$ & 5.25 & $<0.0001$ & $0 \%$ & 0.64 & 12,18 \\
\hline hyperopia (3-4D) vs esotropia & 2 & $19.45(8.79-43.02)$ & 7.33 & $<0.0001$ & $0 \%$ & 0.38 & 12,18 \\
\hline hyperopia (4-5D) vs esotropia & 2 & $44.86(19.57-102.81)$ & 8.99 & $<0.0001$ & $45 \%$ & 0.18 & 12,18 \\
\hline hyperopia ( $>5 \mathrm{D}$ ) vs esotropia & 2 & $134.19(61.35-293.51)$ & 12.27 & $<0.0001$ & $0 \%$ & 0.68 & 12,18 \\
\hline anisometropia vs esotropia & 3 & $1.63(0.32-8.27)$ & 0.59 & 0.55 & $83 \%$ & 0.003 & $12,17,18$ \\
\hline astigmatism vs exotropia & 2 & $1.63(0.10-26.25)$ & 0.34 & 0.73 & $86 \%$ & 0.007 & 12,18 \\
\hline anisometropia vs exotropia & 2 & $1.78(0.14-22.87)$ & 0.44 & 0.66 & $85 \%$ & 0.009 & 12,18 \\
\hline
\end{tabular}

Table 4. Adjusted ORs of the Association of Refractive Errors with Exotropia and Esotropia.

A

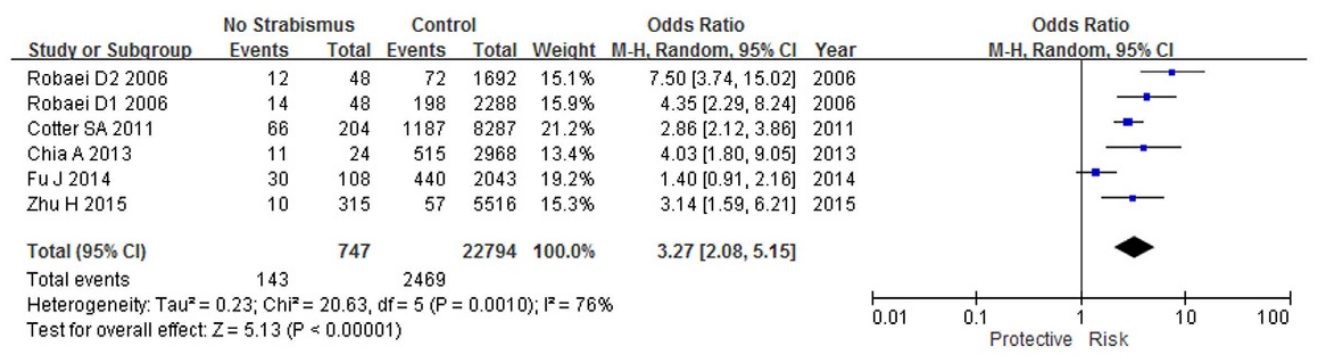

B

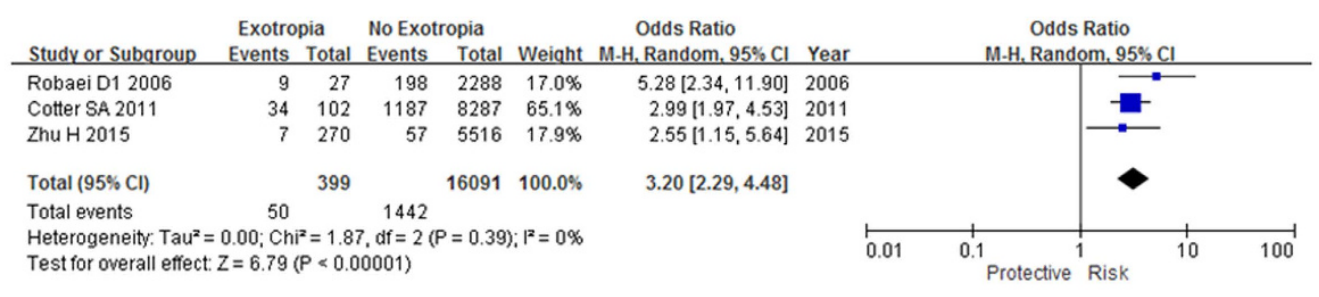

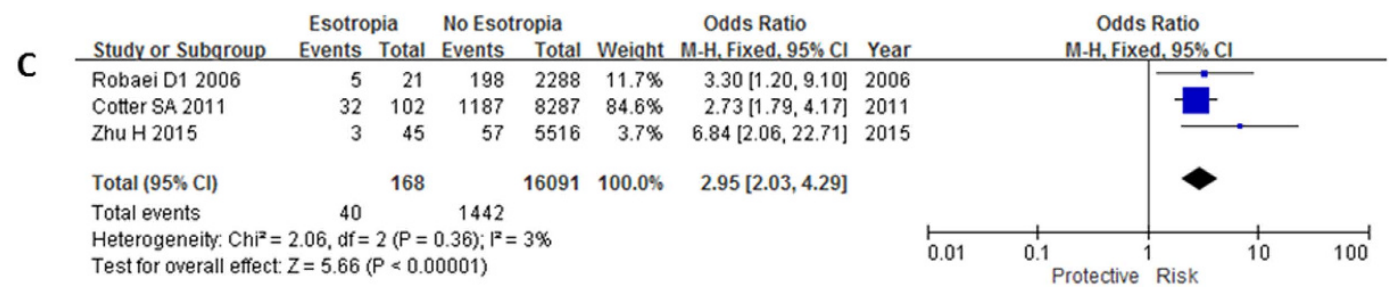

Figure 4. Meta-analysis of the association of astigmatism with different types of strabismus. The bars with squares in the middle represent $95 \%$ confidence intervals (95\% CIs) and odds ratios (ORs). The central vertical solid line indicates the ORs for the null hypothesis. Diamond indicates summary OR with its corresponding 95\% CI. (A) Association between astigmatism and strabismus. (B) Association between astigmatism and exotropia. (C) Association between astigmatism and esotropia.

Association between anisometropia and concomitant strabismus. Six out of seven studies $^{1,11,12,18,23,24}$ have evaluated association between anisometropia and concomitant strabismus. Anisometropia was associated with concomitant strabismus (OR: 5.68, 95\% CI: 2.44-13.23, $\mathrm{I}^{2}=92 \%, \mathrm{P}<0.0001$; Table 2, Fig. 5A). Four studies ${ }^{11,12,17,18}$ have evaluated association between anisometropia and exotropia; and esotropia separately. In subgroup analysis, anisometropia was a risk for both exotropia (OR: 6.56, 95\% CI: $3.19-13.49, \mathrm{I}^{2}=72 \%$, $\mathrm{P}<0.0001$; Table 3, Fig. 5B) and esotropia (OR: 11.29, 95\% CI: 4.22-30.23, $\mathrm{I}^{2}=83 \%, \mathrm{P}<0.0001$; Table 3, Fig. 5C). However, the associations became insignificant after adjusting for confounding factors $(\mathrm{P}>0.05$; Table 4$)$.

Risk of bias assessment and sensitivity analysis. All studies were of high quality indicating low risk of bias when being included in this meta-analysis (Supplementary Table 2). Egger's tests did not show significant findings in all of the analyses (Tables 2 and 3). Furthermore, we performed sensitivity analysis by omitting each study at a time subsequently to confirm the results. The association of hyperopia with exotropia became significant after removing Cotter's study (OR: 9.59, 95\% CI: 6.73-13.65, $\left.\mathrm{I}^{2}=31 \%, \mathrm{P}<0.0001\right)^{12}$. None of the other results was altered in the sensitivity analysis. 


\begin{tabular}{|c|c|c|c|c|c|c|c|c|}
\hline \multirow[b]{2}{*}{ Type of exposure } & \multirow{2}{*}{$\begin{array}{c}\text { No of } \\
\text { Studies }\end{array}$} & \multirow{2}{*}{$\begin{array}{c}\text { Sample } \\
\text { size }\end{array}$} & \multicolumn{3}{|c|}{ Overall effect } & \multicolumn{2}{|c|}{ Heterogeneity } & \multirow[b]{2}{*}{ Reference } \\
\hline & & & OR $(95 \% \mathrm{CI})$ & z score & P Value & $I^{2, \%}$ & $\mathbf{Q}(\mathbf{P})$ & \\
\hline 2-3D vs esotropia & 2 & 12918 & $10.16(1.58-65.38)$ & 2.44 & 0.01 & $92 \%$ & 0.0005 & 12,18 \\
\hline 3-4D vs esotropia & 2 & 12285 & $17.83(10.17-31.25)$ & 10.06 & $<0.0001$ & $0 \%$ & 0.5 & 12,18 \\
\hline 4-5D vs esotropia & 2 & 12062 & $41.01(22.44-74.92)$ & 12.08 & $<0.0001$ & $0 \%$ & 0.99 & 12,18 \\
\hline$\geq 5 \mathrm{D}$ vs esotropia & 2 & 12035 & $162.68(40.91-646.89)$ & 7.23 & $<0.0001$ & $81 \%$ & 0.02 & 12,18 \\
\hline
\end{tabular}

Table 5. Association of Different Severity of Hyperopia with Esotropia.

A

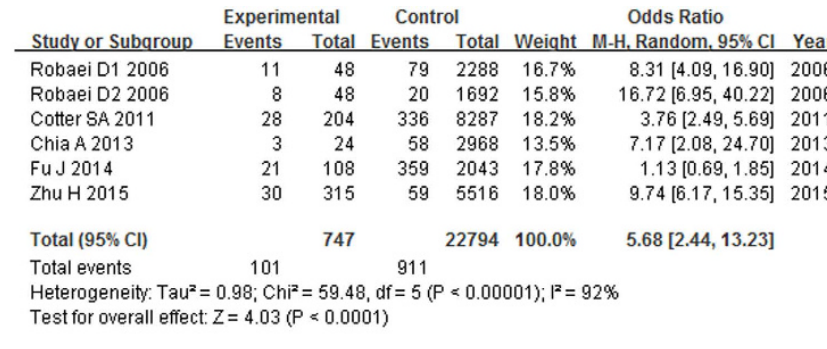

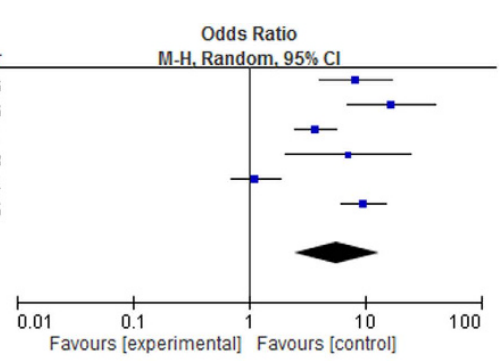

Odds Ratio ${ }^{01} \stackrel{0.1}{\text { Favours [experimental] }^{1}} \stackrel{10}{10}$ Favours [control]

B

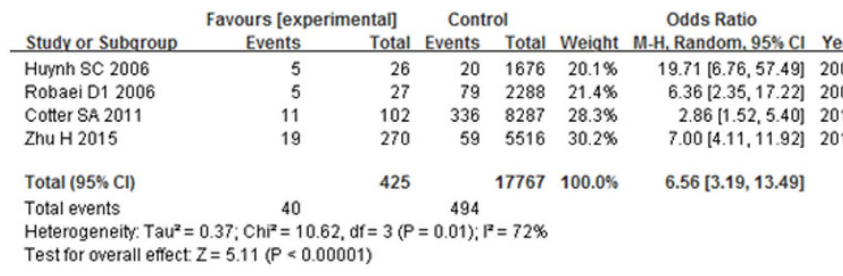

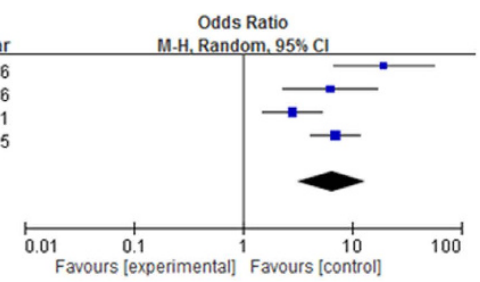

C

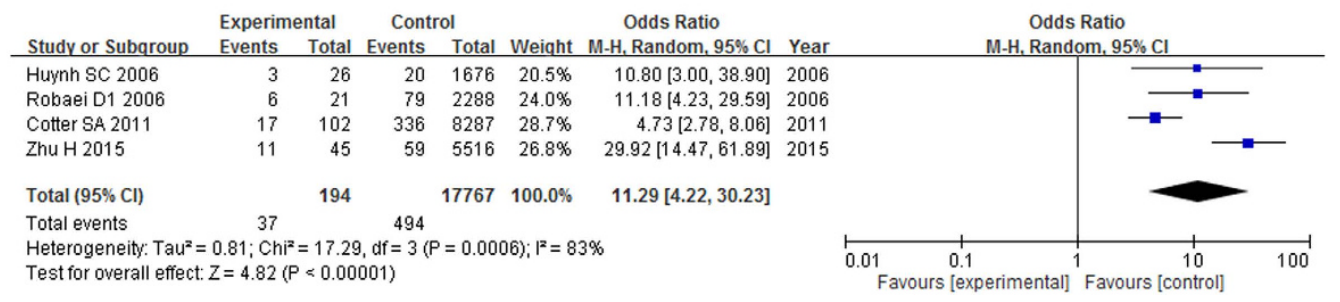

Figure 5. Meta-analysis of the association of anisometropia with different types of strabismus. The bars with squares in the middle represent $95 \%$ confidence intervals (95\% CIs) and odds ratios (ORs). The central vertical solid line indicates the ORs for the null hypothesis. Diamond indicates summary OR with its corresponding 95\% CI. (A) Association between anisometropia and strabismus. (B) Association between anisometropia and exotropia. (C) Association between anisometropia and esotropia.

\section{Discussion}

This systematic review and meta-analysis on 7 large-scale population-based studies involved 23,541 children to determine the association of refractive errors and concomitant strabismus. Based on the synthesized unadjusted ORs, all types of refractive errors (myopia, hyperopia, astigmatism and anisometropia) were confirmed as risk factors for concomitant strabismus.

Among the 7 studies, three have studied the association of myopia with exotropia and esotropia separately. Our results demonstrated no significant association between myopia and esotropia. On the other hand, children with myopia had 5.23-fold increase in risk to develop exotropia than those without significant ametropia. This may explain the high prevalence of exotropia in Asia, in which the prevalence of myopia is much higher ${ }^{11,15,25}$. The exact mechanism of how myopia may lead to exotropia is not certain. We postulated that the fusional control at distant of myopes is weakened due to the blurred distant vision. For near vision, less accommodative effort is required for clear image in myopes due to a larger accommodation $\operatorname{lag}^{26}$, which resulted in less accommodative convergence stimulated ${ }^{27}$. This prolonged suboptimal convergence may lead to breakdown of the fusional control and may predispose to exotropia development. In fact, previous studies have demonstrated that myopes without exotropia had a higher accommodative convergence to accommodation ratio (AC/A) than emmetropes, which also support our postulation ${ }^{28,29}$. The authors believed that myopes may require more convergence per accommodation in order to maintain good fusion and normal alignment, owing to the higher accommodation lag and thus less accommodative convergence stimulated. However, further prospective studies were warranted to confirm the postulation. 
Our results revealed a very strong association between hyperopia and esotropia in a dose-related effect manner. We have therefore identified increasing risk of developing concomitant esotropia with the severity of hyperopia. Based on the meta-analysis of two papers ${ }^{12,18}$ involving around 12000 children, our results showed that hyperopia starting at the $2.00 \mathrm{D}$ to less than $3.00 \mathrm{D}$ imposes more than a 10 -fold increase in risk of developing concomitant esotropia, and even up to 40-fold increase in risk for hyperopia up to 5.00D hyperopia. Strikingly, children with hyperopia of 5.00D or more had 218 times of risk of developing esotropia compared to children with $0.00 \mathrm{D}$ to less than $1.00 \mathrm{D}$. This dose-related effect is highly relevant to public health. Health care providers should be cautioned in that children with moderate to high hyperopia should be closely monitored for the risk of developing into esotropia.

When pooling up the unadjusted ORs of three articles, which have separated into esotropia and exotropia, astigmatism was also found to be a risk for both esotropia and exotropia. However, the results need to be interpreted with cautions, because the confounding effect of spherical myopia and hyperopia has not been adjusted in the analysis. In the seven studies for this meta-analysis, only two reports have provided the adjusted ORs for the effects of astigmatism to exotropia. No association was found between astigmatism and exotropia based on the pooled adjusted ORs. Therefore, further studies were needed to confirm the association.

Anisometropia was found to be associated with strabismus and both esotropia and exotropia based on pooled unadjusted ORs. This can be attributed to the much reduced binocularity in children with anisometropia ${ }^{30}$. However, the pooled adjusted OR did not support the association of anisometropia with exotropia and esotropia. Therefore, there is still no definite conclusion on their relationship and further studies are required to confirm the association.

In this meta-analysis, all included studies were population-based studies. The results obtained are of epidemiological relevance. Furthermore, we used risk of bias assessment tools for observational study recommended by MOOSE guidelines and Cochrane handbook for Systematic Reviews, which showed all included studies were of good quality. Sensitivity analysis has been conducted to further confirm our findings and no significant publication bias has been found. However, all the 7 reports were cross-sectional studies. Further longitudinal studies are warranted to establish a causal relationship between the two conditions. Moreover, we found the definition of refractive errors varied among studies, which could be a major source of heterogeneities. In our meta-analysis, we accounted for heterogeneities by using random-effect model and sensitivity analysis.

In summary, we confirmed that myopia increased the risk of exotropia. Hyperopia was associated with increased risk of esotropia in a dose-dependent manner. We also reported a suggestive association of astigmatism and anisometropia with concomitant strabismus, which should be further confirmed in follow-up studies. Refractive errors are extremely common especially in Asian populations. Strabismus is a difficult ophthalmic disorder that disrupts vision and depreciates quality of life. Investigations are warranted to understand the pathophysiology for the associations between refractive errors and concomitant strabismus.

\section{References}

1. Fu, J. et al. Prevalence of amblyopia and strabismus in a population of 7th-grade junior high school students in Central China: the Anyang Childhood Eye Study (ACES). Ophthalmic Epidemiology 21, 197-203 (2014).

2. Group, M.-e. P. E. D. S. Prevalence of amblyopia and strabismus in African American and Hispanic children ages 6 to 72 months: the Multi-ethnic Pediatric Eye Disease Study. Ophthalmology 115, 1229-1236. e1221 (2008).

3. Samarawickrama, C., Fotedar, R., Mitchell, P. \& Rose, K. Refractive error, strabismus, and amblyopia. Ophthalmology 116, 364-365, author reply 365, doi: 10.1016/j.ophtha.2008.09.028 (2009).

4. Chen, X. et al. Prevalence of amblyopia and strabismus in Eastern China: results from screening of preschool children aged 36-72 months. Br J Ophthalmol 100, 515-519, doi: 10.1136/bjophthalmol-2015-306999 (2016)

5. Yam, J. C. et al. Predictive factors affecting the short term and long term exodrift in patients with intermittent exotropia after bilateral rectus muscle recession and its effect on surgical outcome. Biomed Res Int 2014, 482093, doi: 10.1155/2014/482093 (2014).

6. Yam, J. C. et al. Long-term ocular alignment after bilateral lateral rectus recession in children with infantile and intermittent exotropia. J AAPOS 16, 274-279, doi: 10.1016/j.jaapos.2012.01.005 (2012).

7. Bez, Y. et al. Adult strabismus and social phobia: a case-controlled study. J AAPOS 13, 249-252, doi: 10.1016/j.jaapos.2009.02.010 (2009).

8. Olitsky, S. E. et al. The negative psychosocial impact of strabismus in adults. J AAPOS 3, 209-211 (1999).

9. Lin, S. et al. Alcohol use and positive screening results for depression and anxiety are highly prevalent among Chinese children with strabismus. Am J Ophthalmol 157, 894-900 e891, doi: 10.1016/j.ajo.2014.01.012 (2014).

10. Coats, D. K., Paysse, E. A., Towler, A. J. \& Dipboye, R. L. Impact of large angle horizontal strabismus on ability to obtain employment. Ophthalmology 107, 402-405 (2000).

11. Robaei, D., Kifley, A. \& Mitchell, P. Factors associated with a previous diagnosis of strabismus in a population-based sample of 12-year-old Australian children. American Journal of Ophthalmology 142, 1085-1088 (2006).

12. Cotter, S. A. et al. Risk factors associated with childhood strabismus: the multi-ethnic pediatric eye disease and Baltimore pediatric eye disease studies. Ophthalmology 118, 2251-2261 (2011).

13. McKean-Cowdin, R. et al. Prevalence of amblyopia or strabismus in asian and non-Hispanic white preschool children: multi-ethnic pediatric eye disease study. Ophthalmology 120,2117-2124, doi: 10.1016/j.ophtha.2013.03.001 (2013).

14. Wong, T. Y. et al. Prevalence and risk factors for refractive errors in adult Chinese in Singapore. Investigative ophthalmology \& visual science 41, 2486-2494 (2000).

15. Group, E. D. P. R. The prevalence of refractive errors among adults in the United States, Western Europe, and Australia. Archives of ophthalmology 122, 495 (2004).

16. Rong, S. S., Peng, Y., Liang, Y. B., Cao, D. \& Jhanji, V. Does cigarette smoking alter the risk of pterygium? A systematic review and meta-analysis. Invest Ophthalmol Vis Sci 55, 6235-6243, doi: 10.1167/iovs.14-15046 (2014).

17. Huynh, S. C. et al. Prevalence and associations of anisometropia and aniso-astigmatism in a population based sample of 6 year old children. British Journal of Ophthalmology 90, 597-601 (2006).

18. Zhu, H. et al. Association between childhood strabismus and refractive error in Chinese preschool children. PLoS ONE 10 (3) (no pagination) (2015).

19. Higgins, J. P. \& Thompson, S. G. Quantifying heterogeneity in a meta-analysis. Statistics in medicine 21, 1539-1558, doi: 10.1002/ $\operatorname{sim} .1186(2002)$. 
20. DerSimonian, R. \& Laird, N. Meta-analysis in clinical trials revisited. Contemporary clinical trials 45, 139-145, doi: 10.1016/j. cct.2015.09.002 (2015).

21. Kuritz, S. J., Landis, J. R. \& Koch, G. G. A general overview of Mantel-Haenszel methods: applications and recent developments. Annu Rev Public Health 9, 123-160, doi: 10.1146/annurev.pu.09.050188.001011 (1988).

22. Sterne, J. A., Gavaghan, D. \& Egger, M. Publication and related bias in meta-analysis: power of statistical tests and prevalence in the literature. Journal of clinical epidemiology 53, 1119-1129 (2000).

23. Robaei, D. et al. Factors Associated with Childhood Strabismus. Findings from a Population-Based Study. Ophthalmology 113, 1146-1153 (2006).

24. Chia, A. et al. Risk factors for strabismus and amblyopia in young Singapore Chinese children. Ophthalmic Epidemiology 20, 138-147 (2013).

25. Wen, G. et al. Prevalence of myopia, hyperopia, and astigmatism in non-Hispanic white and Asian children: multi-ethnic pediatric eye disease study. Ophthalmology 120, 2109-2116, doi: 10.1016/j.ophtha.2013.06.039 (2013).

26. Nakatsuka, C., Hasebe, S., Nonaka, F. \& Ohtsuki, H. Accommodative lag under habitual seeing conditions: comparison between myopic and emmetropic children. Jpn J Ophthalmol 49, 189-194, doi: 10.1007/s10384-004-0175-7 (2005).

27. Xie, F. et al. [Clinical investigation on AC/A ratio in intermittent exotropia coexisting with ametropia]. Zhonghua Yan Ke Za Zhi 50, 489-493 (2014)

28. Mutti, C. O., Jones, L. A., Moeschberger, M. L. \& Zadnik, K. AC/A ratio, age, and refractive error in children. Am J Ophthalmol 130, $690(2000)$.

29. Gwiazda, J., Thorn, F. \& Held, R. Accommodation, accommodative convergence, and response AC/A ratios before and at the onset of myopia in children. Optom Vis Sci 82, 273-278 (2005).

30. Agrawal, R., Conner, I. P., Odom, J., Schwartz, T. L. \& Mendola, J. D. Relating binocular and monocular vision in strabismic and anisometropic amblyopia. Archives of ophthalmology 124, 844-850 (2006).

\section{Acknowledgements}

This study was supported by the General Research Fund 14111515; and the Direct Grant of the Chinese University of Hong Kong 4054121. We are indebted to Prof Calvin C.P. Pang for his critical review for the manuscript.

\section{Author Contributions}

S.M.T., R.Y.T.C. and S.B.L. contributed equally. S.M.T. did the data collection, data analysis, and data interpretation. She wrote the main manuscript text and prepared the tables and figures. R.Y.T.C. and S.B.L. did the data collection and data analysis and data interpretation. S.S.R. critically revised the manuscript H.H.W.L. critically revised the manuscript W.W.Y.L. critically revised the manuscript W.W.K.Y. critically revised the manuscript L.J.C. critically revised the manuscript S.T.C.K. critically revised the manuscript J.C.S.Y. conceived the study design, supervised the data collection and data analysis and critically revised the manuscript.

\section{Additional Information}

Supplementary information accompanies this paper at http://www.nature.com/srep

Competing financial interests: The authors declare no competing financial interests.

How to cite this article: Tang, S. M. et al. Refractive Errors and Concomitant Strabismus: A Systematic Review and Meta-analysis. Sci. Rep. 6, 35177; doi: 10.1038/srep35177 (2016).

(c) (i) This work is licensed under a Creative Commons Attribution 4.0 International License. The images or other third party material in this article are included in the article's Creative Commons license, unless indicated otherwise in the credit line; if the material is not included under the Creative Commons license, users will need to obtain permission from the license holder to reproduce the material. To view a copy of this license, visit http://creativecommons.org/licenses/by/4.0/

(c) The Author(s) 2016 